\title{
Endoscopic four-branched stent-in-stent deployment of self-expandable metal stents in malignant hilar biliary obstruction
}

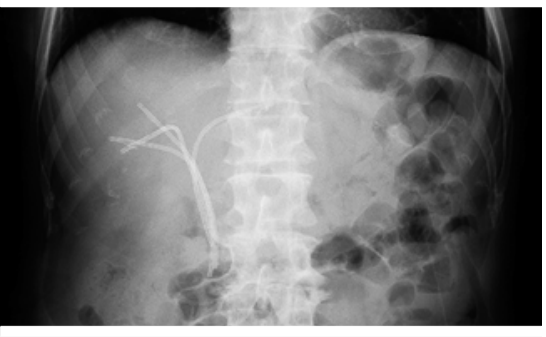

Fig. 1 Radiographic image showing four plastic stents deployed above the sphincter of Oddi in a patient with malignant hilar biliary obstruction.

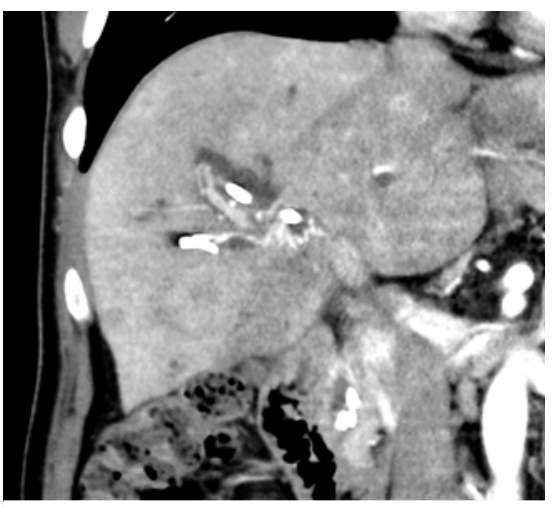

Fig. 2 Computed tomography image on admission showing biliary stent occlusion.

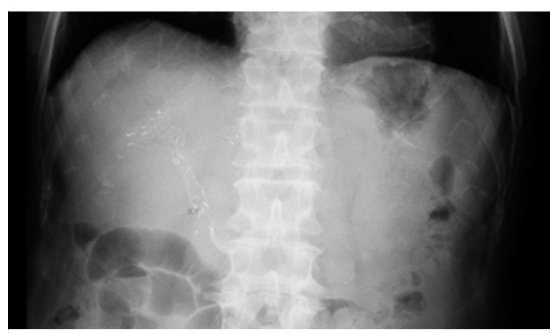

-Fig. 3 Radiographic image showing the four self-expandable metal stents resulting from the successful endoscopic fourbranched deployment using the stent-instent method.

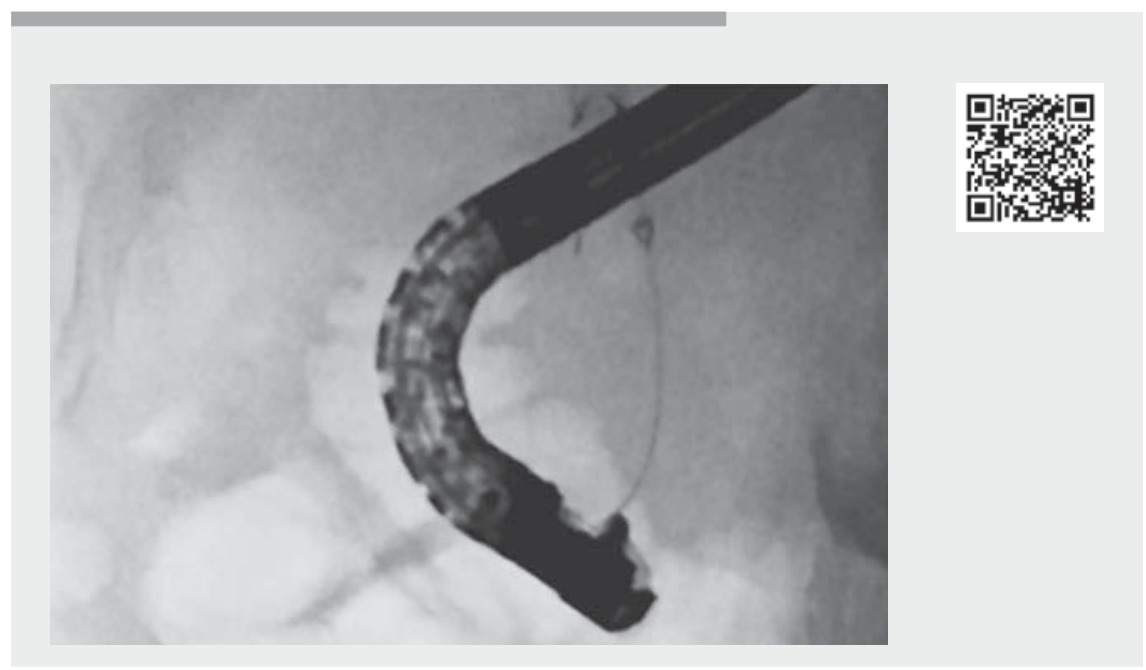

Video 1 Successful endoscopic four-branched deployment using the stent-in-stent method for malignant hilar biliary obstruction.

Malignant hilar biliary obstruction often requires multiple stents for biliary drainage $[1,2]$. However, deploying three or more self-expandable metal stents (SEMSs) is technically challenging [3]. The recently launched, novel uncovered SEMS with slim delivery system (Niti-S Large Cell SR Slim delivery; TaeWoong Medical, Seoul, South Korea) may be combined with a 6-mm balloon catheter (REN biliary dilation catheter; KANEKA, Osaka, Japan) to facilitate the deployment of multiple SEMSs [4]. Here, we report a successful endoscopic four-branched deployment of SEMSs using the stent-in-stent (SIS) method.

A 66-year-old man with metastatic hilar cholangiocarcinoma, who had been undergoing chemotherapy, was admitted to our hospital with acute cholangitis. Initially, 7 months previously, two plastic stents had been deployed for malignant hilar obstruction of Bismuth type 4 in the $\mathrm{B} 2$ and $\mathrm{B} 8$ bile duct segments above the sphincter of Oddi. However, owing to recurrent cholangitis and a liver abscess, a total of four plastic stents were de- ployed 4 months later in B2, B5, B6, and B8 ( $\bullet$ Fig. 1).

A computed tomography scan on admission showed dysfunctional plastic stents and deterioration of his cancer ( $\bullet$ Fig. 2 ). We attempted to deploy four SEMSs using the SIS method ( Video 1 ). First, after removing the plastic stents, we deployed the first and second SEMSs in B6 and B2 using the SIS method. After dilating the mesh of the SEMSs using a balloon catheter, we deployed the third SEMS in B8 using the SIS method. Finally, an attempt was made to deploy a SEMS in B5, but the catheter could not be passed through the mesh of the SEMS. Therefore, a balloon catheter was used to dilate the lumen and mesh of the SEMSs, and the fourth SEMS was then successfully deployed in B5 using the SIS method ( $\vee$ Fig. 3). There were no adverse events such as stent occlusion during the 2 months before the patient's death, which was due to his primary disease.

Endoscopy_UCTN_Code_TTT_1AR_2AZ 


\section{Competing interests}

The authors declare that they have no conflict of interest

The authors

Junichi Kaneko ${ }^{1}$ ๑, Takanori Yamada ${ }^{1}$, Kyoich Fukita', Atsushi Tsuji', Masafumi Nishino', Yurimi Takahashi², Yuzo Sasada²

1 Division of Gastroenterology, Iwata City Hospital, Shizuoka, Japan

2 Division of Hepatology, Iwata City Hospital, Shizuoka, Japan

\section{Corresponding author}

Junichi Kaneko, MD

Division of Gastroenterology, Iwata City

Hospital, 512-3 Ookubo, Iwata-shi,

Shizuoka, Japan

meganerock10@gmail.com
[1] Lee TH, Kim TH, Moon JH et al. Bilateral versus unilateral placement of metal stents for inoperable high-grade malignant hilar biliary strictures: a multicenter, prospective, randomized study (with video). Gastrointest Endosc 2017; 86: 817-827

[2] Puli SR, Kalva N, Pamulaparthy SR et al. Bilateral and unilateral stenting for malignant hilar obstruction: a systematic review and meta-analysis. Indian J Gastroenterol 2013; 32: 355-362

[3] Lee TH, Moon JH, Park SH. Biliary stenting for hilar malignant biliary obstruction. Dig Endosc 2020; 32: 275-286

[4] Inoue T, Ibusuki M, Kitano R et al. A novel large cell-sized stent with slim delivery for combined side-by-side and stent-in-stent placement in malignant hilar biliary obstruction. Endoscopy 2020; 52: E104-E105
Bibliography

Endoscopy 2022; 54: E482-E483

DOI 10.1055/a-1638-9183

ISSN 0013-726X

published online 1.10 .2021

(C) 2021. Thieme. All rights reserved.

Georg Thieme Verlag KG, Rüdigerstraße 14,

70469 Stuttgart, Germany

\section{ENDOSCOPY E-VIDEOS}

https://eref.thieme.de/e-videos

回局 Endoscopy E-Videos is an open access online section, 回和: reporting on interesting cases and new techniques in gastroenterological endoscopy. All papers include a high quality video and all contributions are freely accessible online. Processing charges apply (currently EUR 375), discounts and wavers acc. to HINARI are available.

This section has its own submission website at

https://mc.manuscriptcentral.com/e-videos 